\title{
Organising for self-advocacy in mental health: Experiences from seven African countries
}

\author{
S Kleintjes', C Lund', L Swartz ${ }^{2}$ \\ ${ }^{1}$ Centre for Public Mental Health, Department of Psychiatry and Mental Health, University of Cape Town, Cape Town, South Africa \\ ${ }^{2}$ Centre for Public Mental Health, Department of Psychology, Stellenbosch University, Stellenbosch, South Africa
}

\begin{abstract}
Objective: This paper reports on overarching strategies which supported the establishment and sustainability of 9 mental health self-help organisations in seven African countries. Method: Eleven key informants were identified through snowballing and interviewed regarding their experience in the organisations. Thematic analysis of the interview data and other documentary evidence was guided by a coding scheme derived using a framework analysis approach to defining, categorising, mapping and interpreting textual data. Results: Sustainability strategies include: commitment to members' advocating for their rights and rebuilding their lives within their communities; independent decision-making, user-led membership and leadership; financial selfsufficiency, alliances with donor organisations, non-governmental organisations (NGOs), disabled people's organisations (DPOs) and ministries which support self-determination and promote control over agenda-setting and responsiveness to members' needs. Organisations' work include advocacy to destigmatise mental disorders and promote the protection of users rights, activities to improve access to health care and to income generation and social support, participation in legislative and policy reform, and capacity building of members. Conclusion: Self-help organisations can provide crucial support to users' recovery in resourcepoor settings in Africa. Support of Ministries, NGOs, DPOs, development agencies and professionals can assist to build organisations' capacity for sustainable support to members' recovery.
\end{abstract}

Keywords: Mental health, Self-help, Advocacy, Recovery, Africa

Received: $31-08-2011$

Accepted: 18-05-2012

doi: http://dx.doi.org/10.4314/ajpsy.v16i3.25

\section{Introduction}

The World Health report 2001, Mental Health: New Understanding, New Hope, recommends 10 broad actions which politicians, planners, implementers and civil society should address to reduce the impact of mental illness on population health and wellbeing. ${ }^{1}$ The report includes the recommendation that "communities, families and consumers should be included in the development and decision-making of policies, programmes and services" (ppl 1 1). More recently, the Lancet series on global mental health posed a compelling call for action for effective public health interventions to address the burden of

\section{Correspondence}

Ms S Kleintjes

Valkenberg Hospital, Private Bag X1, Observatory, 7935

Western Cape, South Africa,

email: sharon.Kleintjes@uct.ac.za mental disorders, particularly in low- and middle-income countries. The call suggests that service users and their families be key advocates for the prioritisation of mental health on the agenda of politicians and government departments, be involved in developing human rightsbased services, as well as contributing to direct service delivery as lay workers within community programmes. ${ }^{2}$ Others have also noted the need to develop and support self-help and mutual aid initiatives, given the potential destigmatising impact of having role-models of personal competence among people with psychosocial disability who still face significant stigma attached to their mental health conditions. ${ }^{3}$ These initiatives are particularly relevant in low- and middle- income settings, where the greatest burden of chronic and disabling conditions may be found and where care is most often limited to the already meagre resources of families and community structures. ${ }^{4}$ Formal human resources for mental health are 
insufficient in these settings, or inaccessible, and where organised family and community support programmes are available, these have limited reach relative to service need.s. 5,6

Information on the processes, practices and structures which self-help organisations for people with psychosocial disability have developed to improve their contribution to members' recovery in low and middle income settings is not readily accessible to the policy makers, implementers and practitioners they should influence. This work is reported mainly in grey literature ${ }^{7}$ with peer reviewed publications on the state of user organisations for people with psychosocial disability in Africa sparse at present. ${ }^{8,9}$ A World Health Organisation report on resources for mental health included information on seven African countries, Burundi, the Congo, Eritrea, Ethiopia, Nigeria, South Africa and Uganda. User associations were reported in 3 of 7 countries, and family associations in 2 of 6 countries. ${ }^{10} \mathrm{~A}$ WHO Afro-region audit of mental health resources in Africa reports data on the number of user and family associations among member states. ${ }^{11}$ These reports provide information on the number of these organisations in these countries, but do not report on the challenges which these organisations face in supporting their members. This paper contends that the user-led organisations for people with psychosocial disability provide "networks of engagement" 12 , through which affected people and their carers can individually and collectively participate in promoting their own health and recovery. This paper reports on the overarching strategies which 9 national self-help organisations in seven African countries have employed to promote the recovery of people living with psychosocial disability in an African context, and provides insights into lessons from these experiences which may strengthen the development of similar organisations promoting empowerment of people living with psychosocial difficulties elsewhere in Africa.

\section{Methods}

\section{Document review}

Internet searches for websites, minutes of meetings, conference proceedings, training reports, and audiovisual material was conducted to help identify organisations and potential informants, and to provide background information to augment the interview data. Informants also volunteered documents on the history and activities of the organisations.

\section{Semi-structured interviews}

Informants: Ten national mental health self-help organisations were identified through internet searches and snowballing. Potential informants were contacted, recruited and informed consent obtained for participation obtained via email, fax and telephone. We were unable to recruit informants from MindFreedom, Kenya due to telecommunication difficulties. Table I lists the remaining 9 organisations. We interviewed four women and seven men prominently involved in the leadership of the organisations, based in seven countries, Ghana, Kenya, Rwanda, South Africa, Tanzania, Uganda and Zambia.

Interview schedule: We drafted a semi-structured interview schedule to guide enquiry based on a scoping of the literature on mental health user organisations in developed and developing countries. ${ }^{13}$ The interview schedule was refined based on input from a review group comprised of 3 user advocates and 4 public sector mental health practitioners working in mental health policy and service development, and user advocacy support in South Africa. They commented on appropriateness of terminology and comprehensiveness of the issues covered. The interview schedule addresses issues such as the vision and objectives of the organisation, organisational structure, setting up and sustaining the organisation, leadership, membership, technical support and funding.

Data collection: Interviews were conducted telephonically between October 2009 and July 2011. The pace of data collection was influenced by the recruitment process.

\section{Table I: National self-help organisations for people with psychosocial disability in Africa}

\begin{tabular}{|c|c|c|c|c|c|}
\hline Name & Country & Inception & NPO status & Members & Coverage \\
\hline MindFreedom Ghana & Ghana & 2004 & 2005 & Users & Capital city \\
\hline Mental Health Society of Ghana (MEHSOG) & Ghana & 2002 & 2009 & Users & Capital city and northern region \\
\hline Users and Survivors of Psychiatry Kenya (USPKenya) & Kenya & 2007 & 2008 & Users and carers & Some districts \\
\hline $\begin{array}{l}\text { National Organisation of Users and Survivors of Psychiatry } \\
\text { Rwanda (NOUSPR) }\end{array}$ & Rwanda & 2007 & 2007 & Users and carers & Some districts \\
\hline South African Mental Health Advocacy Movement (SAMHAM) & South Africa & 2009 & No & Users & Advocacy group in 8 provinces \\
\hline The Ubuntu Centre & South Africa & 2007 & 2008 & Users & Capital city \\
\hline Mental Health Uganda MHU) & Uganda & 1999 & 2000 & Users and carers & Several districts \\
\hline Mental Health User Organisation of Zambia (MHUNZA) & Zambia & 1997 & 2001 & Users & Capital city and surrounds \\
\hline $\begin{array}{l}\text { Tanzanian Users and Survivors of psychiatry organisation } \\
\text { (TUSPO) }\end{array}$ & Tanzania & 2004 & 2006 & Users and carers & Some districts \\
\hline
\end{tabular}


Correct contact details were not readily available. Once contacted, some informants were selected through a process of nomination by their organisations; others requested an e-introduction by the referring informant before granting an interview. One or more interviews of approximately 90 minutes each were conducted and recorded with informants' permission. Lines of enquiry not included in the interview guide were followed where informants introduced new themes relevant to the study, and informants were interviewed until it became clear that no new information on the themes were emerging from their interviews.

Data management and analysis: Recorded interviews were transcribed verbatim, and transcripts checked for accuracy. Thematic analysis of the data was guided by the themes preset in the interview schedule, with new themes added as determined by the data. ${ }^{14}$ This framework analysis approach was developed for use in applied policy research directed at obtaining information which can inform actionable recommendations ${ }^{15}$ and is therefore suited to the focus of this study.

Confidentiality: Informants' personal details are omitted and informant quotations delinked from their organisation

Data verification: A draft of this report was made available to participants to review the authors' interpretation of the data. Informants commented by telephonic interview or email.

\section{Ethics}

Permission to conduct the study was obtained from the Research Ethics Committee of the Faculty of Health Sciences, University of Cape Town, South Africa.

\section{Results}

\section{Organisational Purpose}

The impetus for starting the organisations, in all countries, arose from members' experience of stigma, discrimination and social exclusion, and a desire to provide members with a "voice" to advocate for their basic human rights. Members are also provided with a support system within which they can re-build their self-confidence, skills and relationships needed for purposeful living.

\section{... stigma brings about denial of the human race and certain ignorance of ... care givers, so we've started this to break that old traditional mindset, (...) to create a platform for our voices to be heard (...) we are also people, we also need services, we can also contribute (...) economically and socially.}

\section{The organisations}

Mental Health Uganda (MHU) and the Mental Health Users Network of Zambia (MHUNZA) were formed more than a decade ago, with the remaining organisations established four to nine years ago. Ubuntu, South Africa, MHUNZA and the Tanzanian Users and Survivors of Psychiatry Organisation (TUSPO) were founded by charismatic leadership with firm beliefs in the need to change the unequal societal participation of their members.

\begin{abstract}
If you want my main message, it is that people with mental illness have the right to access anything that impacts on their lives, just like any other person, irrespective of gender, age, colour, religion, vocation or any other factor that can distinguish them from any other person.
\end{abstract}

MindFreedom Ghana (MFGhana), the Mental Health Society of Ghana (MEHSOG), Users and Survivors of Psychiatry Kenya (USPKenya), the National Organisation of Users and Survivors of Pyschiatry (NOUSPR), Rwanda and MHU started with a handful of motivated people pooling their collective energy to start support groups and advocacy initiatives .
I gave a short paper about my family's struggle with mental health problems. (...) I was not the only user (...) present (...) two of them (...) when they heard me they also came and spoke with me (...) and together (...) five of us, were the founder members of this organization.

The South African Mental Health Advocacy Movement (SAMHAM) is a project of the largest mental health nongovernmental organisation (NGO) in South Africa, the South African Federation for Mental Health (SAFMH), which provides infrastructural support, mentoring and training to the movement. SAMHAM comprises a national user forum which draws representation from provincial user forums within SAFMH-affiliated NGOs based in the 9 provinces of South Africa.

\section{Membership}

Members are recruited through member-driven public awareness and through family and community member referrals. Members of SAMHAM, MHU and MHUNZA are also referred by service providers at mental health clinics. While family members and other supporters can participate in the work of the organisations, formal membership is restricted in most organisations to people with firsthand experience of mental illness.

\section{Staffing}

MHU, MEHSOG and USPKenya have paid positions for limited office and/or programmatic support. One provincial forum in SAMHAM employs a skilled service user to develop and manage its user forum. Other than these few posts, organisations rely on members' and volunteers' time for organisational work. Informants from MEHSOG, USPKenya, NOUSPR, TUSPO, MHU and MHUNZA noted the importance of carers' involvement to the success of their work, as the majority of members live with their families. NOUSPR described their work as follows:

...We assess medical, we assess social, we assess the economical situation of the member and then we decide according to the assessment who is the volunteer who will be giving help (...) after a certain period the caregiver will take over and the volunteer will visit the home to chat over the subject. 
Seven of the nine organisations have non-user mental health professionals and technical experts on their advisory boards, as paid administrative or programme managers, or to provide technical, financial and in-kind resources.

\section{Leadership and decision-making}

All organisations felt that key decision-making of the organisation must be driven by its members.

We as service users understand our issues and needs more...service users are more at ease listening to another service user...(Organization) is a service user movement, a service user should drive the movement. .

With the exception of SAMHAM, the organisations have independent leadership and membership structures and processes for organisational decision-making. Informants emphasised the importance of having control over agendasetting and the pace of development to ensure that organisations remain sustainable, and responsive to members' needs.

(International NGO) had some self-help groups and they wanted us to merge with them, so that it becomes one big organisation (...) I realised that we don't want to get lost in that (...) we will work hand in hand with them (...) initially we were thinking if there was only one national movement, that their voices will be strong(...) later we said, no, there could be three or four organisations that is fighting for the same cause, but there are various ways in which we are doing it.

Informants felt that while alliances are necessary, a selfdetermination agenda is best supported by embedding strong user leadership and participation into the institutional culture and operating frameworks of the organisations

There's a given percentage of office bearers who must be users, but also (...) a culture must be cultivated where users enjoy certain rights within the organisation.... we have been very careful with the kind of service providers and professionals we engage with (...) those that adhere to the ideology here which is the userbased approach.

\section{Technical support and funding}

All nine organisations have benefited from encouragement, technical expertise or financial support to establish and sustain the organisations. Leaders of MFGhana and Ubuntu focus primarily on advocacy, for example, and have been mentored by the World Network of Users and Survivors of Psychiatry (WNUSP), an international organisation of (ex) users/survivors of psychiatry focusing on protecting the human rights of people with psychosocial disability. MEHSOG, USPKenya, NOUSPR, MHU and TUSPO obtained assistance with establishing peer support activities from local and international NGOs and DPOs.
An organization must be two or three years old, must have audited account... seeing that you are just starting out, we didn't have those qualifications (...) we have done some projects in partnership that has enabled us to get the experience and also the capital (...) to get along with our work.

Ministries have also supported a few of the organisations. In Uganda, in 1997, the Ministry of Health's strong support for establishing a "voice" for user advocacy led to the establishment of a longstanding alliance with an international disabled people's organisation (DPO) who has over the years provided extensive technical and financial support to the development of MHU.

our peers in (DPO's country) who are our major development partners took us for a three day visit to see exactly what they do, challenges they go through and their best practices. There is a lot we learnt from that visit and also it fostered solidarity in the user/survivor movement as we continue advocating for our inherent rights

In Zambia, the Ministry of Health linked MHUNZA to a national NGO already funded for HIV/AIDS prevention and treatment programmes. Mental health related awareness-raising is now included in the work of this NGO. Similarly, TUSPO has the verbal support of its Ministry of Health:

I met a mentally ill person in the game reserve, walking alone, there are elephants there. That shocked me... I met with the Minister of Health who was also shocked....he gave me authority to start as a $C B O$, to mobilise people, to train them...

Direct access to operational capital was seen as central to support user independence in developing and expanding organisational activities. Project expansion in SAMHAM, a project of South Africa's largest mental health NGO, for example, is dependent on approval and funding of its initiatives by the national and provincial boards of management of the SAFMH. Ubuntu, South Africa, having made a principled stand not to partner with non-user organisations, enjoys peer support from fellow DPOs internationally but struggles to secure regular funding to expand its activities.

Registration as a NGO is a key strategy to support independent fundraising for programmatic and operational costs. Eight of the nine organisations are formally registered as non-profit organisations, and had registered within one to three years of launching their organisation. SAMHAM in South Africa saw registration as a strategy to pursue in the future, when the organisation felt more ready for independent work.

Donor funding has accelerated the work of some of the organisations. MHU in Uganda and MHUNZA in Zambia, established in the 1990s, have both received support to access funding by their Ministries of Health. The Ugandan ministry supported donor-funded MHU to establish contact with donors for technical and grant-based financial support. 
MHUNZA, with its advocacy activities coupled to another government funded project, unlike $\mathrm{MHU}$, has no independent funding to support expansion of its work. MHU has gone on to securing other external grants independently. External grants have also created opportunities for strengthening the capacity of MEHSOG, MFGhana and TUSPO.

\begin{abstract}
... mental illness and poverty is a vicious cycle. No one will employ you when you are mentally ill. Most of the mentally ill people are selfemployed....the financial aid has given us the capacity to build up what we must build up .. none of us had the financial capacity to put up the organisation that we have today.
\end{abstract}

\section{Organisational activities}

Common threads in the organisations' work include advocacy to destigmatise mental disorders and promote the protection of users' rights, activities to improve access to health care and to income generation and social support, participation in legislative and policy reform, and capacity building of members.

\section{Advocacy}

Rights protection and destigmatisation through public awareness and education is a key activity of all organisations, and is directed at changing the attitudes and practices of the general public, civil leaders, policy makers and service providers.

...my hope is that mentally ill people will be
treated the same way as somebody with
diabetes, or hypertension, or any other
condition... that they will be treated with respect,
as a human being, that is what I basically work
for.

Advocacy strategies include the development of written, audio-visual and dramatic anti-stigma and rights promotion material, mass action such as awareness raising marches, as well as monitoring media discrimination and using media for antidiscrimination work. Mental health priorities are promoted through members' representation on local, national and international forums- including broader disability structures through which they can lobby for improved access to mental health services, housing, work, education, and basic amenities. Two informants reported serving as representatives on international disability initiatives informing global discussions on the interpretation and implementation of the provisions of the United National Convention on the Rights of Persons with Disabilities (UNCRPD).

Members of MFGhana, USPKenya, Ubuntu, MHU and MHUNZA are also regularly involved in bringing international attention - through presentations at international meetings to the situation of people with psychosocial disability on the African continent.

Let us also go beyond the medical approach (...) Because that large number of people being pushed on the edge can contribute to national development, who knows? (...) we are asking that we put in place some deliberate policy and programmes (...) Include them in developmental programmes and see how much they can contribute (...) So we are also attaching mental health to development.

\section{Legislation and policy development}

Informants believe that lobbying for inclusion and improved service provision will only be effective within a supportive legal and policy framework. The rights-based provisions of the United Nations Convention on the Rights of Persons with Disabilities (UNCRPD) was mentioned by nine of the informants as the basis on which this work should be premised.
(user organization) is key in this point in history in this country to play it's role (....) government has to fulfill its international obligations to which it's committed in the convention (...) but it has to be done with consultation.

MFGhana, MEHSOG, MHU and MHUNZA are already advocating for greater consultation of users by government in legislative, policy and service reviews.
when the (legislative review) committee was set up, they should have added some users. They didn't do that (...) the problem is they are used to users not being heard. (...) the onus now is on us to find ways of penetrating to be heard and to be seen.

Ghana, Kenya, Uganda and Zambia were reviewing their mental health legislation and mental health policies at the time of the interviews, and informants confirmed that they are either working toward or are already being consulted during these crucial developments. NOUSPR in Rwanda currently focuses on raising awareness amongst lawmakers through personal contact with and distribution of pamphlets to parliamentarians. Both South African informants felt that consultation of users in drafting the country's most recent mental health policy (1997) and legislation (2002) was cursory. In South Africa, in April 2012, the National Ministry of Health hosted provincial consultations and a national summit on mental health policy and legislation. Stakeholder perspectives in the draft mental health policy presented at the summit included the views of service users. The involvement of people with psychosocial disability was also an explicit inclusion principle of all the consultations, and Ubuntu and SAMHAM respectively chaired and presented their advocacy work during the session on Social Mobilisation and Advocacy at the national summit. In Kenya, having missed the revision of their national policy when newly established, USPKenya earmarked impending revisions to their constitution as a first formal contribution to influencing legislative change.

\footnotetext{
... if you look out for us without hearing us, we are not very sure those laws will be representing our views. (...) (lawmakers) have an important role to make sure the issues about service users are included in the Constitution with sensitivity.
} 
TUSPO in Tanzania, with relatively recent policy (2006) and legislation (2008) in place, would like to secure support to initiate a campaign focusing on law and policy implementation.

\section{Public health services and supports}

Improving access to basic mental health care is a significant focus of the organisations' work. Most of the other organisations, in addition to lobbying for improved government services, also provide members and their carers with psycho- education for symptom management, and psychosocial support. NOUSPR uses members and carer volunteers to conduct home visits, facilitate community meetings and support groups, MEHSOG, USPKenya, SANHAM, South Africa and MHU run peer- led self help groups.

we enlighten them that... it's an ordinary illness.... when they come to the meeting... they meet their fellow sufferers... they become happier, they stop thinking they are the only person suffering from this illness in the family, or in the community... we advise the parents to love them while they are taking the medication...(NGO) helps them with a loan... without money and without food the medication would be difficult to eat.

Some self help groups in Rwanda and Uganda also organise group savings schemes to fund medication for users who cannot readily access this from the public service. While there is a strong emphasis on supporting user capacity for selfmanagement of their illness, organisations were clear that this does not replace members' need for and right to access public-funded mental health services. Members need for community-accessible, affordable medication was spontaneously mentioned by nine of the eleven informants.

\section{Sustainable livelihoods}

Sustainable income generation is a strong focus of the work of MEHSOG, USPKenya, NOUSPR, TUSPO, MHU and MHUNZA because of the strong link between poverty and mental illness experienced by their members. Informants noted that members' ability to generate income, to build their work skills, and to enjoy the self-esteem which rewarding work can bring is often severely eroded by mental illness, particularly where they have little access to effective mental health care. Families may reject sufferers due to stigma, and the financial and emotional difficulties experienced when supporting family members with untreated mental illness. While access to basic treatment can improve members' contribution to family wellbeing and thereby alter negative relationships within overstretched families, recovered users still face discrimination in securing work.

there have been times when we have been successful in lobbying for services (...) but when people get services then they say, ah, but now we need work, I need an income, I need to look after myself (...) we realized that its not only just work, but we need meaningful and sustainable livelihoods.
In some countries, members and their carers are supported to identify income -generation opportunities and to develop the skills to set up, run and fund these initiatives. Members may also set up income generating cooperatives with other members. Group savings schemes (Uganda, Ghana) and small start up loans (MEHSOG, MHU and MHUNZA) provide start up capital for income generation projects for members as local banks will not fund projects run by people with psychosocial disabilities.
...income generating activities is one of - it is the main broker of stigma. Because if a member is capable of running a certain business with the help of the caregiver, you find they are integrated in the home (...) he feels he has a place in the home, we find the income generation helps with the recovery of the member.

Community experience of the positive contribution of these projects, and those involved in them, can slowly erode negative attitudes, as well as rebuild members' confidence to step into mainstream life, as illustrated by this account of a local farmer living with a psychosocial disability:

we have promoted him as a role model... he is doing something that is quite a feat in his condition, that is sustainable and meaningful, so it earns him respect in the community... He has been in some government programmes looking for role model farmers, and he was picked many times within his community...

\section{Regional collaboration and capacity development}

Eight of the nine organisations noted that their organisational agendas must be responsive to broader contextual issues affecting people living with psychosocial difficulties within African settings.

\section{In Africa, we have to have our own situation in perspective before we roll out our advocacy agenda, we cannot just go with what western advocacy are saying}

\section{... people from the West are talking of people who have survived the services. In Africa ....it's very few who can get to those services.}

To provide mutual support for afro-conscious practices within these organisations, a regional body for mental health self-help organisations, the Pan African Network of Users and Survivors of Psychiatry (PANUSP) was launched in 2005 at a conference in Kampala, Uganda. Members communicate mainly by email, teleconferencing or at conferences when members are funded to contribute to proceedings as part of their advocacy work. Five of organisations also reported having members funded to provide training, mentoring and other technical support to starting similar organisations in the region.

In August 2011 , PANUSP was awarded its first 
successful grant to conduct strategic planning and capacity development activities for leaders of the organisations listed in Table I and emerging leadership from Nigeria and Malawi. At a meeting in October 2011 in Cape Town, to strengthen its identity as a disabled peoples' organisation which identifies with the principles of the CRPD, the organisation changed its name to the Pan African Network of Persons with Psychosocial Disabilities (PANUSP). It was also felt that "users and survivors" does not as aptly as the new name, convey the plight of Africans living with psychosocial disability who do not have access to services and supports to promote their recovery on the continent. Participants at the meeting drafted the Cape Town Declaration, 16 October 2011 , which sets out PANUSPs' members' hopes and aspirations for the future as a DPO for people living with psychosocial disability in Africa. We quote from the declaration:

We are deeply concerned about the extent of suffering experienced by our brothers and sisters on our vast continent. Poverty, human rights violations and psychosocial disability go hand in hand. We know that there can be no dignity where poverty exists. No medicines or sophisticated western technology can eradicate poverty and restore dignity.... We wish for a better world in which all people are treated equally, a world where human rights belong to everyone. We invite you to walk beside us. We know where we want to go. "'

\section{Discussion}

This study reviewed the work of 9 self help organisations established within the past 16 years to support the recovery of people with psychosocial disability in seven African countries. Results support the contention that self-help initiatives can serve as valuable vehicles for participation of users in their own and others' recovery processes. ${ }^{16}$ There are several threads common to the experiences of these organisations which offer insights into what motivates and can support the work of these organisations in low- resourced settings. These are discussed under two broad themes, the value of organising and the need for alliance-building

\section{The value of organising}

Anthony succinctly describes the process of recovery as the "development of new meaning and purpose in one's life (...) beyond the catastrophic effects of mental illness". Empowerment for recovery requires a shift in one's belief about potential for agency, real opportunity to exercise that belief through active participation in decisions and activities, and the removal of personal and external barriers to that participation. Such empowerment is the central purpose of self-help organisations for people living with psychosocial disability ${ }^{18}$, providing opportunity for active participation of members in self-identified activities directed at supporting their own and others recovery.

\section{Participation}

The organisations' primary focus is to create new hope for recovery through the experience of self-representation, self-determination, meaningful participation and mutual support. ${ }^{19}$ Organisational and personal goals are set by members, and members are supported to develop their capacity for involvement in the implementation of actions aimed at achieving these goals. Active participation of members is not merely a principled approach, but the cornerstone on which members' confidence and abilities are rebuilt to enable satisfying participation in community life. ${ }^{18}$

\section{Advocacy and peer-led service delivery.}

A second focus of these organisations is to harness and strengthen opportunities for active participation in desired roles in society, and the removal of barriers to participation in these roles. People with psychosocial disability still face legal exclusion from or impediments to the exercise of their civic rights (for example, to contract for marriage, property and business, to choose where to live, or to freely voice opinions) and their political rights (that is, their ability to impact on the laws and policies which govern community life). These structural impediments, combined with the disempowering impact of reduced socioeconomic status, and the struggles of living with a psychosocial disability, hamper their ability as individuals to advocate for change which will enable them to work toward roles of their choice in society. ${ }^{20}$ Drawing on the resources of members and "empathic allies"21, and on the power of unified action by members ${ }^{22}$ self-help organizations provide a powerful, unified platform for individuals and families affected by psychosocial disability to promote their inclusion in civic, economic and politicallife. They can be vehicles for concerted lobbying and action around issues which individuals and families would otherwise not have recourse to address.

At the same time, while advocating for the acceptance of the right to inclusion of people with psychosocial disability ${ }^{23}$, and working to develop regulatory frameworks which support this inclusion is necessary ${ }^{24}$, this is not sufficient to ensure their participation in community, political, economic and social life. Results of this study indicate that even the most basic benefits which social and regulatory discourse envision are often not available to these citizens through public services in low- and middle-

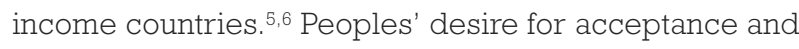
participation as equal family and community members may be tempered by the impact of inadequate treatment and supports on their ability to meaningfully participate in family and community life. Poor ability to contribute to their own and their family's economic and social wellbeing may deepen the material and relational poverty within which members live. ${ }^{25}$ Self-help organisations in these settings therefore cannot only advocate for change, if they are to remain responsive to their members' needs. They have to extend their brief to include direct peer-led service delivery, as these organisations have done, for example, through peer support programmes (such as wellnessmonitoring, counseling and psycho-education in support groups) and self-help initiatives (such as the setting up of
${ }^{1}$ The full declaration is available at http://wWw.panusp.org/aboutus/the-history-of-panusp/ 
cooperatives for treatment and income-generation). ${ }^{26}-$ Limited formal resources, a philosophy of self determination and a rootedness in Ubuntu- humanity through interconnectedness and solidarity with others ${ }^{27}$ seem to simultaneously influence these organisations' reliance on their members and their families for the sustainability of the organization. Without members' work, there may be little or no access to basic treatment and support for other members. Without access to basic care and opportunity for self-sufficiency, members are less able to contribute to the work of their organization and the key role it plays in their own and others' recovery.

\section{Strength through diversity}

Results suggest that diversity in organisational development is needed to ensure that organisations stay attuned to member priorities, and to maximise the number of people and areas of expertise available to contribute to these organisations' work. In some instances, organisations in this study have focused on an advocacy agenda with their available resources, while other organisations have focused on building local structures to support members' involvement in localised self-help initiatives The pace and focus of development should at all times be set by the organisations to ensure sustainability of their work. There is a "continuum of involvement" possible and members or organisations should dictate at which levels and in which way they which to participate. ${ }^{28}$

\section{The need for alliances}

Alliance-building has been central to support self-help organisations in this study. Results support allies adopting a development focus to the establishment and expansion of these organisations: technical and economic support must contribute to self-sufficiency over time, and increased capacity to contribute to future developments within other established, and newly emerging self-help organisation. ${ }^{29}$ The role of ministries, public sector workers, development agencies and NGOs, and of self-help organisations in building such capacity is briefly explored below.

\section{Ministries}

The organisations in this study see the ratification of the $\mathrm{UNCRPD}^{30}$ by their governments as key to support the work of the psychosocial disability lobby within their countries. Ratification of this Convention sets the gold standard informing these organisations' rights-based lobby for change in support of members' desire for selfdetermination, inclusion and direct participation. Areas emerging from these results where Ministries could support the development of these organisations include ensuring that organisations are included in existing opportunities for NGO funding, and public input to policy and service development, provision of resources for training and skills development, as well as brokering new opportunities for financial and technical support of the organisations' work.

\section{Public sector departments and service providers} Informants' stories identify policy makers and implementers within the health, social security, education and skills development, employment, labour, agriculture and finance sectors as key actors whose decisions are potentially enabling - or disabling - of the recovery of people with psychosocial disability. Within these sectors, acknowledgement and responsiveness to the broader social drivers which influence recovery also presents practitioners with a transformative challenge to service development and provision.31 At local level, nondiscriminatory and recovery-oriented practitioner attitudes and practices, willingness to share expertise, skills and decision-making platforms can support the achievements of the collective goals and individual aspirations of members of these organisations.

\section{Development agencies and NGOs}

These young self-help organisations are simultaneously juggling establishment of good governance structures, development of capacity to be responsive to members' needs, and the generation of funds for their mental health work, a historically under-funded area of work globally. ${ }^{5}$ Donor organizations and development agencies can support these developments by expanding their brief to include funding opportunities for mental health on the continent, including funding of self-help organizations. ${ }^{24}$ Support is needed for the establishment of self-help organisations at country level, the development and implementation of a consulted programme of action in the region, and for skills development to sustainably operationalise country and regional activities. Organisations reviewed in this study, for example, have developed their capacity by building alliances with more established international and regional DPOs and NGOs, before launching out independently. Results point to the fact that capacity development premised on mutual exchange and learning over time can benefit both the supporter organisation and the local self-help organisation as each is exposed to the others' innovative solutions to challenges presented by local contexts.

\section{Mental health self-help organisations}

Newly established organisations can benefit from collaborating with other self-help organisations in-country, and across the region. Mutual support and cooperation has been a key strategy for dealing with the paucity of resources in individual organisations and across the region. Members of more established organisations or with specific areas of skill have volunteered their time for the conceptualisation and operationalisation of PANUSP at regional level, and are providing training and support to recently established self-help organisations.

\section{Conclusion}

In Africa, self-help organisations offer their members new hope for recovery and participation in community life. Their task is monumental, their key resource the very people they have set out to serve. Active participation of members in advocacy, provision of support in accessing health and other support services and the development of income generation opportunities, in collaboration with allies, provide crucial support to users' recovery in resource-poor Africa. Ministries, NGOs, DPOs, 
development agencies and service providers can provide vital support to building capacity within these initiatives in the region.

\section{Acknowledgements}

The authors wish to acknowledge the late Professor Alan J. Flisher, Department of Psychiatry and Mental Health, University of Cape Town, South Africa, for co-supervision of this work prior to his death in April 2010. This report was supported by the Hendrik Vrouwes Research Scholarship, BOE Trust, Cape Town, South Africa, and the African Doctoral Dissertations Research Fellowship, the African Population and Health Research Center (APHRC), Kenya.

\section{References}

1. World Health Organisation. The World Health Report 2001. Mental health: New understanding, new hope. Geneva: World Health Organisation; 2001.

2. Lancet Global Mental Health Group. Scale up services for mental disorders: a call for action. Lancet 2007 October; 370:1241-1247.

3. Saraceno B, van Ommeren $M$, Batnije R, Cohen A, Gureje O, Mahoney J, et al. Barriers to improvement of mental health services in low-income and middle-income countries. Lancet 2007;370(9593): $1164-1174$.

4. Beaglehole R, Epping-Jordan J, Patel V, Chopra M, Shah E, Kidd $M$, et al. Improving the prevention and management of chronic disease in low-income and middle-income countries: a priority for primary health care. Lancet 2008;372: 940-949.

5. Saxena S, Thornicroft $G$, Knapp $M$, Whiteford H. Resources for mental health: Scarcity, inequity and inefficiency. Lancet 2007 September;370:878-889.

6. Alem A, Jacobsson L, Hanlon C. Community-based mental health care in Africa: mental health workers' views. World Psychiatry 2008;7:54-57.

7. Barbarto A, Vallarino M. Community mental health in low income countries. A way forward. Milan, Italy: Mario Negri Institute for Pharmacological Research; 2010.

8. Katontoka S. User networks for Africans with mental disorders. Lancet 2007 September; 370(9591):919-920.

9. Kleintjes S, Lund C, Swartz L, Flisher AJ and the MhaPP Research Programme Consortium. Mental health care user participation in mental health policy development and implementation in South Africa. International Review of Psychiatry 2010;22(6):568577.

10. World Health Organisation. Mental health systems in selected low- and middle-income countries: a WHO-AIMS cross-national analysis. Geneva: World Health Organization; 2009.

11. Lund, C., Van Heyningen, T., \& Majavu, M. Evaluation of the WHO African Regional Strategy for Mental Health (2000-2010). Report for the African Regional Office of the World Health Organization (AF/09/352191). Cape Town: Department of Psychiatry and Mental Health, University of Cape Town; 2010

12. HASCAS. Making a real difference: Strengthening Service User and Carer Involvement in the NIMHE (Final report), United Kingdom: NIMHE, National Health Services; 2005.

13. Arksey H, O'Malley L. Scoping studies: towards a methodological framework. International Journal of Social Research Methodology 2005;5(8):19-32.

14. Ritchie J, Spencer L. Qualitative data analysis for applied policy research. In: Bryman A, Burgess RG, editors. Analysing qualitative data. London: Routledge; 1994.173-194.

15. Lacey A, Luff D. Trent focus for research and development in primary care: An introduction to qualitative analysis. Sheffield, United Kingdom: Trent Focus Group; 2001.

16. Thornicroft G, Tansella M, Law A. Steps, challenges and lessons in developing community mental health care. World Psychiatry 2008;7:87-92.

17. Anthony WA. Recovery from mental illness: The guiding vision of the mental health service system in the 1990s. Psychosocial Rehabilitation Journal 1993;16(4):11-23.

18. Salie MA. User/survivor initiatives: Non professional, peer-based, community support services in mental health; successes and challenges to date. In: Barbarto A, Vallarino $M$, editors. Community mental health in low income countries. A way forward. Milan, Italy: Mario Negri Institute for Pharmacological Research; 2010. P. 59-66.

19. Farkas $M$. The vision of recovery today: what it is and what it means for services. World Psychiatry 2007;6(2):68-74.

20. Chan KKL, Chui, YL. The politics of citizen formation: political participation of mental health service users in Hong Kong. Asian Journal of Social Sciences 2007 35:195-215.

21. McDaid S. An equality of condition framework for user involvement in mental health policy and planning: evidence from participatory action research. Disability and Society 2009 June;24(4):461-474.

22. Kelly BD. The power gap: Freedom, power and mental illness. Social Science \& Medicine 2006;63:2118-2128.

23. Kakuma R, Kleintjes S, Lund C, Drew N, Green A, Flisher AJ, and the MHaPP Research Programme Consortium. Mental health stigma: what is being done to raise awareness and reduce stigma in South Africa? African Journal of Psychiatry 2011;13:116-124.

24. Faydi E, Funk M, Kleintjes S, Ofori-Atta A, Ssebunnya J, Mwanza J, et al. An assessment of mental health policy in Ghana, South Africa, Uganda and Zambia. Health Research Policy and Systems. 2011 Apr; 9:1 1 online April 2011 doi: 10.1186/1478-4505-9-17.

25. World Health Organisation. Mental Health and Development Report. Geneva: World Health Organisation; 2010.

26. Kayiira JL. Psychiatric users and caregivers unite to contribute to mental health and own development in Uganda: Mental Health Uganda (MHU). In Barbarto A, Vallarino M, editors. Community mental health in low income countries. A way forward. Milan, Italy: Mario Negri Institute for Pharmacological Research; 2010. P. 55-58.

27. Murithi T. A local response to the global human rights standard: the ubuntu perspective on human dignity. Globalisation, Societies and Education 2007; 5:3, 277-286.

28. Tritter JQ, MCCallum A. The snakes and ladders of user involvement: Moving beyond Arnstein. Health Policy 2006;76:156-168.

29. BasicNeeds. Community mental health practice. Seven essential features for scaling up in low-and middle-income countries. Bangalore, India: BasicNeeds; 2009.

30. United Nations. Comprehensive and integral international convention on the protection and promotion of the rights and dignity of persons with disabilities [report online]; 2006. Available from: wWw.un.org/disabilities/convention/conventionfull.shtml

31. Topor M, Borg S, Di Girolamo S, Davidson L. Not just an individual journey: social aspects of recovery. International Journal of Social Psychiatry 201 1;57(1):90-99. 